Vol. 2 | No. 3 | 2021 | Hal. 199-204

\title{
PENGEMBANGAN SUMBER DAYA MANUSIA DENGAN PELATIHAN TANAMAN MELALUI MEDIA HIDROPONIK
}

\author{
Nurhidayah*, Muhammad Dzunun Almisry, Yuyun Wijiastuti, Dita Octavia, Dinda Nur \\ Kholifah Safitri, Ni'matul Magfiroh, Meilinda Hamida Hasan, Silvy Putri Wulandari, \\ Ahmad Wanto Baihaki, Ighfirlana, Reiki Vega Diondah, Muhammad Ilyas Oktavian \\ Abdul Latif, Rizky Amelia Husniyah \\ Fakultas Ekonomi dan Bisnis, Universitas Islam Malang \\ *korespondensi email: aya@unisma.ac.id
}

\begin{abstract}
ABSTRAK
Pengembangan sumber daya manusia merupakan salah satu faktor permasalahan yang sering dihadapi dibeberapa wilayah desa. Hal tersebut diakibatkan oleh pandemi Covid-19 yang menerjang di akhir tahun 2019. Dampaknya, sumber daya masyarakat mengalami penurunan baik secara finansial maupun penghasilan, salah satunya dialami oleh Desa Tunggulwulung. Program Kandidat Sarjana Mengabdi Universitas Islam Malang dalam menciptakan sumber daya manusia yang baik dapat dilakukan melalui penggerakan sebuah pelatihan. Program ini menekan masyarakat desa agar dapat menciptakan sumber daya manusia yang unggul melalui pelatihan. Langkah-langkah yang dilaksanakan dalam pelaksanaan program ini adalah mengadakan sebuah pelatihan tanaman melalui media hidroponik. Berbagai langkah ini dilakukan dalam jangka waktu sehari dengan persiapan membutuhkan waktu dua minggu. Diharapkan adanya kegiatan ini dapat menumbuhkan sumber daya manusia yang unggul dengan memanfaatkan pelatihan tanaman melalui media hidroponik yang dijadikan hasil usaha atau UMKM selain itu juga meningkatkan keterampilan ibu-ibu PKK untuk bisa menanam sayuran dengan media hidroponik.
\end{abstract}

Kata Kunci: pemberdayaan sumber daya manusia; hidroponik; UMKM

\section{PENDAHULUAN}

Desa Tunggulwulung adalah sebuah desa di kecamatan Pandaan, Kabupaten Pasuruan, provinsi Jawa Timur, Indonesia. Dengan perkiraan luas total wilayah Desa Tunggulwulung yaitu $2.8 \mathrm{~km}$ persegi (1,1 mil persegi) Tunggulwulung terbagi menjadi beberapa dusun, antara lain: dusun kedawung, dusun tegalwaringin, dusun rejoso, dusun tenggulunan, dusun candi dan dusun ketemas. Desa Tunggulwulung berada di lokasi yang strategis, cukup dekat dengan Pusat Kecamatan Pandaan yang dikenal sebagai desa salah satunya bermata pencaharian petani. Namun dengan kondisi pandemi Covid-19 yang menerjang sejak akhir tahun 2019 menyebabkan masyarakat desa mengalami penurunan finansial maupun penghasilan. Oleh karena itu, Kandidat Sarjana Mengabdi (KSM)-Tematik Kelompok 40 menciptakan program Pelatihan Tanaman Melalui Media Hidroponik dengan meninjau berbagai aspek wilayah yang sering dijadikan tempat tinggal bagi sebagian masyarakat Indonesia, karena suhu didataran rendah cukup nyaman karena tidak terlalu dingin sehingga jenis tanaman seperti kangkung sebagai media untuk pelatihan hidroponik. 
Ide pelatihan ini didasari oleh kondisi Covid-19 yang diharapkan masyarakat Desa Tunggulwulung bisa memanfaatkan pelatihan ini menjadikan masyarakat memiliki sumber daya manusia yang unggul, menjadikan pelatihan ini inspirasi masyarakat dalam menciptakan hasil usaha. Kandidat Sarjana Mengabdi (KSM)-Tematik mengajak ibu-ibu PKK Tunggulwulung dalam merealisasikan program kegiatan ini dengan menerapkan protokol kesehatan, sebab pandemi Covid-19 sehingga semua kegiatan masih dibatasi.

Sayuran hidroponik adalah sayuran yang dihasilkan dengan system hidroponik. Keunggulan dari sayuran hidroponik adalah steril, segar dan tanpa pestisida (Halim, 2016). Saat ini perkembangannya sangat pesat terutama di daerah perkotaan. Kangkung merupakan tanaman yang tumbuh dengan cepat dan memberikan hasil dalam waktu 25-30 hari sesudah dilakukan penyemaian. Tanaman kangkung biasa tumbuh sepanjang tahun bisa ditemukan di dataran tinggi ataupun dataran rendah khususnya kawasan yang berair dengan suhu 20-30oC. Ada dua jenis kangkung yang biasa di konsumsi yaitu kangkung air dan kangkung darat. Kangkung air mempunyai daun panjang dengan daun agak tumpul berwarna hijau kelam biasa ditanam di pinggir kolam atau rawa-rawa. Sedangkan kangkung darat mempunyai daun yang panjang ujungnya rancing biasanya di tanam di tempat yang agak kering (Sitti Nurdianti Sholihat, M Ramdlan Kirom dan Indra Wahtudhin Fathonah, 2018). Kangkung memiliki manfaat yaitu: (1) mencegah anemia, (2) baik untuk kesehatan mata, (3) perbaikan untuk otak, (4) perbaikan untuk jantung, (5) menurunkan kondisi kolesterol, dan (6) mencegah diabetes.

Teknologi hidroponik merupakan metode bercocok tanam tanpa tanah, tetapi menggunakan larutan nutrisi sebagai sumber. Teknologi hidroponik ini memiliki banyak keunggulan dibandingkan dengan teknik bercocok tanam secara tradisional. Keunggulan hidroponik antara lain ramah lingkungan, produk yang dihasilkan higienis, pertumbuhan tanaman lebih cepat, kualitas hasil tanaman dapat terjaga dan kualitas dapat lebih meningkat. Sayuran yang diproduksi dengan sistem hidroponik juga menjadi lebih sehat karena terbebas dari kontaminasi logam berat industry yang ada di dalam tanah, segar dan tahan lama serta mudah untuk di cerna (Saskia Ulfa Afrani, 2018).

Sistem penanaman hidroponik dikembangkan berdasarkan alasan bahwa jika tanaman diberi kondisis yang optimal maka hasil produksinya maksimal. Tanaman dengan budidaya hidroponik lebih mudah mengatasi masalah pengairan yang berlebihan karena sisa air yang mengalir akan langsung keluar, berbeda dengan media tanah yang cenderung menyimpan. Oleh karena itu, perlu adanya kegiatan pelatihan hidroponik bagi masyarakat Desa Tunggulwulung sangat berperan penting bagi pemberdayaan sumber daya manusia.

Kegiatan Pelatihan Hidroponik dengan sasaran utama pada Desa Tunggulwulung yaitu ibu-ibu PKK Desa Tunggulwulung, Kecamataan Pandaan, Kabupaten Pasuruan diharapkan dapat membantu masyarakat Desa Tunggulwulung dalam pemberdayaan dan pengembangan sumber daya manusia yang sudah termasuk dalam salah satu program kerja Kandidat Sarjana Mengabdi (KSM)-Tematik Kelopok 40 Universitas Islam Malang sebagai bentuk pengabdian.

\section{METODE}

Pelatihan tanaman melalui media hidroponik dilakukan kepada ibu-ibu PKK Desa Tunggulwulung dan dilaksanakan di Aula Balai Desa Tunggulwulung. Metode yang digunakan dalam pelaksanaan pelatihan ini yaitu dengan ceramah (penjelasan secara langsung), demonstrasi, dan evaluasi. Hal ini dimaksudkan agar ibu-ibu PKK paham bagaimana budidaya hidroponik mulai dari proses awal hingga panen.

Adapun alat dan bahan yang dibutuhkan adalah (1) botol bekas $600 \mathrm{ml}$, (2) gunting/cutter, (3) kain flannel/busa bekas, (4) bibit tanaman unggul, (5) air bersih, dan (6) 
pupuk/nutrisi cair. Pelaksanaan pelatihan tanaman melalui media hidroponik ini dilakukan dengan dua tahap, yaitu: (a) tahap penyemaian, dan (b) pindah tanam.

Adapun langkah pelaksaan pelatihan sayuran hidroponik ini adalah (a) tahap penyemaian: (1) siapkan bahan dan alat yang dibutuhkan seperti bibit tanaman hidroponik, gunting/cutter, kantong plastik hitam, busa, dan botol bekas, (2) pastikan botol bekas masih tampak kokoh dan tidak berkerut, (3) ambil alat pemotong yang sudah disediakan, kemuadia potong leher botol menjadi dua bagian, (4) lalu potong busa menjadi persegi dan beri lubang pada bagian tengah busa untuk tempat bibit nantinya, (5) basahi busa dengan air dengan cara diciprat agar tidak terlalu lembab, (6) tanam benih tanaman ke dalam lubang yang telah dibuat di atas busa sampai terisi penuh, (7) kemudian tempatkan media tanam busa kedalam wadah persegi, (8) letakkan wadah untuk penyemaian benih di tempat yang gelap dan jauh dari sinar matahari, (9) pantau perkembangan benih setiap hari hingga pecah benih, (10) jika benih tanaman sudah berkecambah di pindah ke tempat yang terkena sinar matahari, (11) kemudian siram tanaman secara rutin setiap hari dan harus terkena sinar matahari.

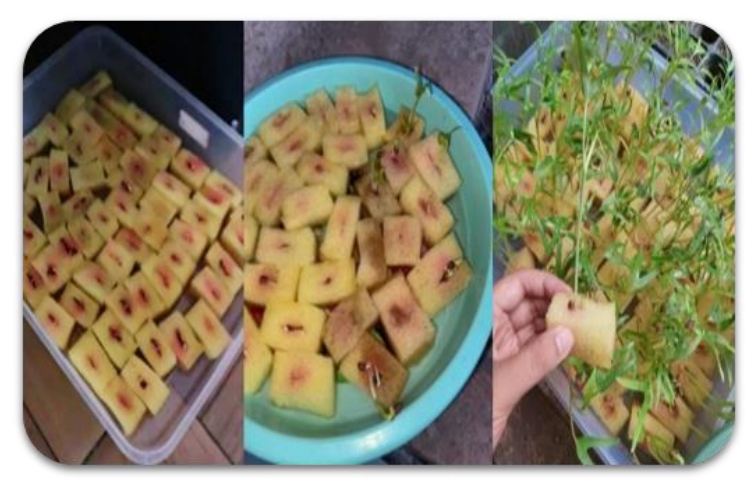

Gambar 1. Benih umur 1-14 hari

Adapun Langkah-langkah (b) tahap pindah tanam adalah sebagai berikut: (1) siapkan botol bekas yang sudah dibuat sebelumnya, (2) tuangkan air bersih yang sudah dicampur dengan pupuk/nutrisi cair pada bagian bawah botol, (3) kemudian ambil bagian leher botol, pindahkan media tanam busa yang sudah ditumbuhi kecambah, dan dan akar dengan hatihati ke dalamnya, (4) ganti air bersih secara berkala agar tanaman tidak sampai gagal panen, (5) letakkan tanaman di tempat yang terkena sinar matahari, dan (6) lakukan perawatan secara intensif dengan rutin mengganti pupuk/nutrisi cair agar tanaman tetap terjaga.

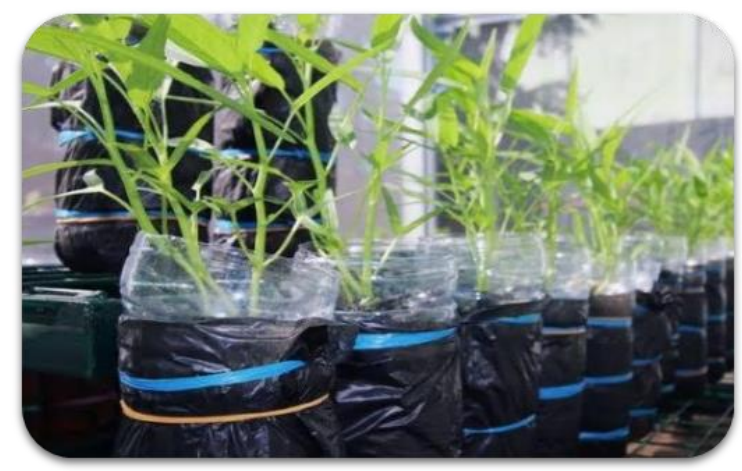

Gambar 2. Kangkung umur 21 - 25 hari

\section{HASIL DAN PEMBAHASAN}

Pemberdayaan adalah keadaan yang terjadi atau hal-hal yang dilakukan di lingkungan masyarakat dengan upaya membangun pembangunan yang bertumpu pada 
masyarat itu sendiri. Tujuan dari dilakukannya pemberdayaan masyarakat adalah untuk membuat masyarakat menjadi berdaya. Berdaya yang dimaksud ialah upaya yang memungkinkan masyarakat untuk bertahan dan mengembangkan diri untuk mencapai kemajuan, madiri dan sejahtera (Danial et al., 2019). Dari uraian diatas tercermin peranan masyarakat yakni sebagai pelaku dan sasaran pemberdayaan dari berbagai sektor, serta peranan pemerintah maupun lembaga pendidikan yaitu sebagai vasilitator agar terwujudnya masyarakat yang berdaya.

Kegiatan pengabdian kepada masyarakat kali ini adalah memberikan pelatihan kepada para ibu-ibu rumah tangga di Desa Tunggulwulung agar lebih produktif walaupun di masa Pandemi Covid-19 dan dapat memahami dan menerapkan budidaya kangkung secara hidroponik, sehingga dapat membantu perekonomian keluarga, karena dapat dikomersialkan yaitu di jual pada pedagang sayur.

Konsep hidroponik sendiri merupakan sistem budidaya pertanian yang dilakukan secara horizontal, baik dalam ruangan maupun diluar ruangan dengan menggunakan media utama yaitu air (Mas'ud, 2009). Sistem budidaya pertanian secara hidroponik merupakan konsep penghijaun yang cocok untuk daerahperkotaan dan lahan terbatas (Tom, 2005). Selain itu juga dilihat dari sisi ekonomi, menanam sayuran dengan konsep hidroponik sangat menguntungkan. Tanpa membutuhkan biaya yang tinggi dan dengan perawatan yang relative mudah warga bisa memenuhi kebutuhan sayur mayor tanpa harus membeli.

Pelaksanaan program kegiatan Pelatihan Hidroponik dilaksanakan setelah dilakukan pengamatan pada kondisi sumber daya masyarakat Desa Tunggulwulung. Ditemukan bahwa akibat kondisi pandemi Covid-19 sejak tahun 2019, membuat perlahan kualitas sumber daya manusia masyarakat desa menurun, walaupun Desa Tunggulwulung dikenal sebagai desa tani, namun masih saja terdapat problematika sehingga berdampak pada finansial dan pendapatan masyarakat desa yang menurun.

Dengan adanya program kegiatan ini, masyarakat bisa memanfaatkan dengan menyerap ilmu pelatihan hidroponik sehingga bisa merealisasikan di rumah masing-masing untuk memenuhi kebutuhan rumah tangga. Terlebih penanaman hidroponik terjangkau mudah, murah, efisien dan cepat, tak memerlukan lahan kosong demi membudidaya penanaman hidroponik. Kegiatan Pelatihan Hidroponik ini diharapkan dapat dilaksanakan dengan memperoleh hasil yang optimal. Dengan begitu pula harapan kami bisa dimanfaatkan menjadi hasil usaha atau merambah ke dunia UMKM.

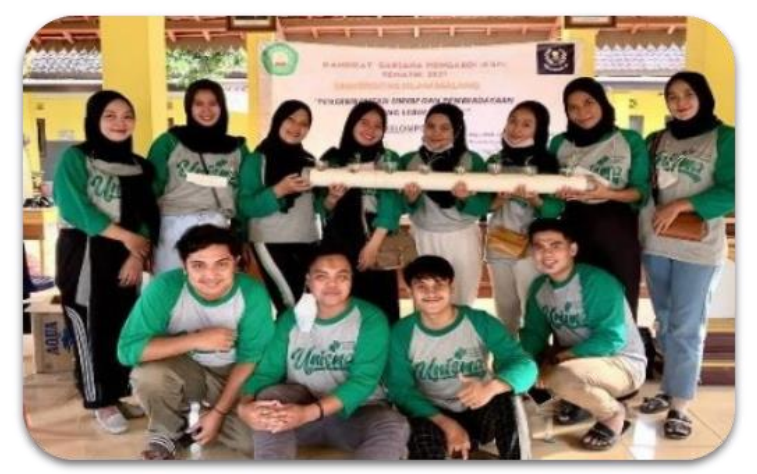

Gambar 3. Tanaman hidroponik yang sudah dipindah ke pipa 


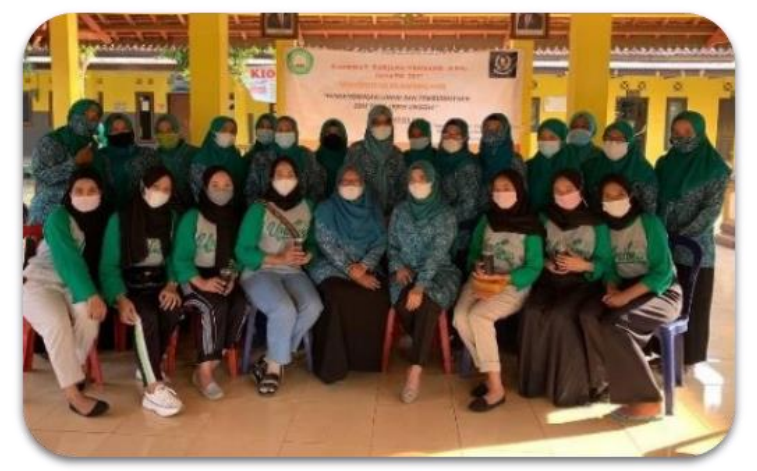

Gambar 4. Pelatihan hidroponik bersama Ibu-ibu PKK

\section{KESIMPULAN}

Pengembangan sumber daya manusia merupakan salah satu faktor permasalahan yang sering dihadapi dibeberapa wilayah desa. Hal tersebut diakibatkan oleh pandemi Covid-19 yang menerjang di akhir tahun 2019. Dampaknya, sumber daya masyarakat mengalami penurunan baik secara finansial maupun penghasilan, salah satunya dialami oleh Desa Tunggulwulung. Program Kandidat Sarjana Mengabdi (KSM)-Tematik Kelompok 40 Universitas Islam Malang dalam menciptakan sumber daya manusia yang baik dapat dilakukan melalui penggerakan sebuah pelatihan. Program ini menekan masyarakat desa agar dapat menciptakan sumber daya manusia yang unggul melalui pelatihan. Langkahlangkah yang dilaksanakan dalam pelaksanaan program ini adalah mengadakan sebuah pelatihan hidroponik. Diharapkan adanya kegiatan ini dapat menumbuhkan sumber daya manusia yang unggul dengan masyarakat bisa memanfaatkan dengan menyerap ilmu pelatihan hidroponik sehingga bisa merealisasikan di rumah masing-masing untuk memenuhi kebutuhan rumah tangga. Terlebih penanaman hidroponik terjangkau mudah, murah, efisien dan cepat, tak memerlukan lahan kosong demi membudidaya penanaman hidroponik. Dengan begitu pula harapan kami bisa dimanfaatkan menjadi hasil usaha atau merambah kedunia UMKM. Selain itu juga untuk meningkatkan pengetahuan, minat dan keterampilan masyarakat untuk lebih produktif dan kreatif di masa pandemi Covid-19 ini. Dan Ibu-ibu PKK juga memberi respon yang sangat positif terhadap kegiatan pemberdayaan sumber daya manusia dengan pelatihan tanaman melalui media hidroponik dan menilai kegiatan pelatihan ini sangat bermanfaat.

\section{UCAPAN TERIMA KASIH}

Ucapan terima kasih disampaikan kepada Lembaga Penelitian dan Pengabdian kepada Masyarakat (LPPM), Universitas Islam Malang, yang telah memberikan kesempatan untuk dapat melakukan program Kandidat Sarjana Mengabdi (KSM)-Tematik Berbasis Keilmuan dan Domisili Kelompok 40 Universitas Islam Malang. Selain itu, kami juga mengucapkan terima kasih kepada Kepala Desa Tunggulwulung telah memberikan dan mempercayakan kami dalam terjun dan mengabdi kepada masyarakat Desa Tunggulwulung, dan kepada Ibu-Ibu PKK yang bersedia membantu dan menyukseskan program pengabdian sumber daya manusia dengan melakukan pelatihan tanaman melalui media hidroponik.

\section{DAFTAR RUJUKAN}

Azizu, A. M., Rendi, D., Kurniawan, C., Agribisnis, P., Pertanian, F., Muhammadiyah, U., Prodi, M., Fakultas, A., Universitas, P., Buton, M., \& Pendahuluan, A. (2021). Pelatihan Budidaya Kangkung Sistem Hidroponik di Kota Baubau. 5(1), 265-275. 
CINDY CAHYANING ASTUTI, INTAN ROHMA NURMALASARI, F. N. H. (2020). Peningkatan Swasembada Pangan dengan Penanaman Kangkung Hidroponik. Prosiding Seminar Nasional Unimus, 3, 1.

Danial, A., Darusman, Y., Mustakim, \& Herwina, W. (2019). Model Pemberdayaan Masyarakat Melalui Pola Magang Tradisional Dalam Upaya Peningkatan Wirausaha Masyarakat. Jurnal Inovasi Hasil Pengabdian Masyarakat (JIPEMAS), 2(1), 31-48. https://doi.org/10.33474/jipemas.v2i1.2182

Efficiency, T., Unit, D. M., \& Productivity, T. F. (2020). Pelatihan Budidaya Tanaman Kangkung Hidroponik dengan Memanfaatkan Barang Bekas pada Masyarakat Rt 04, Rw 06, Desa Kalijurang, Kecamatan Tonjong, Kabupaten Brebes. 2018-2020.

Mayssara A. Abo Hassanin Supervised, A. (2014). Pelatihan Budidaya Sayuran Hidroponik di masa Pandemi bagi Ibu-ibu di Desa Nyatnyono Kecamatan Ungaran Barat Kabupaten Semarang. Paper Knowledge . Toward a Media History of Documents.

Mujriati, A., Nafisah, K., Hayatunnisa, K., \& Japa, L. (2021). Pelatihan Budidaya Sayuran Hidroponik Menggunakan Sistem Wicks Sebagai Usaha Pemberdayaan Masyarakat di Desa Cenggu. Jurnal Pengabdian Magister Pendidikan IPA, 4(2). https://doi.org/10.29303/jpmpi.v4i2.717

Ruswaji, R., \& Chodariyanti, L. (2020). Pemberdayaan Masyarakat Desa Kepada Kelompok Ibu-Ibu Pkk dan Karang Taruna melalui Program Pelatihan "Hidroponik." Jurnal Abdimas Berdaya : Jurnal Pembelajaran, Pemberdayaan Dan Pengabdian Masyarakat, 2(01), 1. https://doi.org/10.30736/jab.v2i01.32

Sholihat, S. N., Kirom, R., \& Fathonah, I. W. (2018). Pengaruh Kontrol Nutrisi pada Pertubuhan Kangkung dengan Metode Hidroponik Nutrient Fillm Technique (NFT). E-Proceeding of Engineering, 5(1), 910-915 